\title{
EUS E OLHARES SOBRE OS OUTROS: relatos de Hans Staden e suas releituras cinematográficas
}

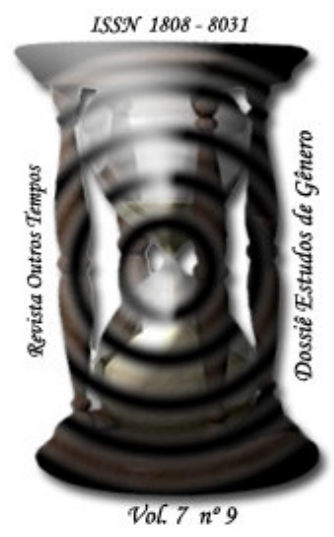

\author{
Vitória Azevedo da Fonseca \\ Doutora em História pela Universidade Federal Fluminense (UFF) \\ vitoria.azevedo@gmail.com
}

Resumo: O artigo propõe considerações sobre as relações de alteridade estabelecidas entre o relato de Hans Staden e suas posteriores adaptações para o cinema nos filmes Hans Staden (Luiz Alberto Pereira, 1999) e Como era gostoso o meu francês (Nelson Pereira dos Santos, 1971). Na análise passeamos por diversas temporalidades de eus e outros. Há um eu autor (Hans Staden) que descreve um outro desconhecido (indígenas), pautado em outros conhecidos. Há eus muito distantes no tempo (cineastas) que utilizam o relato deste outro, para falar de um outro outro ainda mais distante. Assim, nesse calderão temporal vamos discutir um processo de leituras e releituras do passado, no cinema.

Palavras-chave: Hans Staden, cinema brasileiro, alteridade

Abstract: The paper presents considerations about the alterity relations between the report of Hans Staden and later film adaptations, Hans Staden (Luiz Alberto Pereira, 1999) and Como era gostoso meu francês (Nelson Pereira dos Santos, 1971). The analysis goes through several temporalities of selves and others. There is an author self (Hans Staden) that describes the unknown other (Indians), guided by known others. There are selves very far away in time (moviemakers) which use the account of that other, in order to talk about another other, even more distant. In this "time caldron", we will discuss a process of reading and rereading of the past, in cinema.

Key-words: Hans Staden, brazilian cinema, alterity 
O historiador lida constantemente com um outro, distante no tempo e no espaço. Mas, o que é falar desse outro? Quem é o outro? E quem é esse eu que fala de um outro? Durante muito tempo - e para alguns, ainda hoje -, a história seria o discurso verdadeiro (sobre o outro) por excelência. Acreditava-se que o historiador descrevia o passado como "realmente" era. Ou seja, que conseguiria, sem nenhuma parcialidade, falar de fato sobre o outro apagando as marcas da sua presença e do seu presente.

Mas, não é apenas o historiador que se aventura nas searas das temporalidades. Existem diversas formas artísticas e culturais que tem como personagens esses outros distantes no tempo, e também no espaço. O cinema é um desses meios que algumas vezes tomam como foco a alteridade do passado.

No entanto, nem a história, nem o cinema, ou melhor, nem um historiador nem um cineasta conseguem apagar as marcas do próprio discurso e do próprio fazer. E o outro do qual parece se falar não é o outro do qual se fala. Há uma dinâmica intrincada entre o autor e o relato, entre os eus e os outros nesse processo de representação/interpretação do passado.

Neste artigo, proponho algumas reflexões sobre a dinâmica do eu e do outro nos relatos do viajante Hans Staden, e sua visão sobre os índios tupinambás, e a sua posterior transformação em narrativas cinematográficas: uma delas na década de 1970, com o filme Como era gostoso o meu francês (Nelson Pereira dos Santos, 1971) e a outra da década de 1990, com o filme Hans Staden (Luiz Alberto Pereira, 1999).

Nessa dinâmica de eus e outros, os trabalhos de Tzvetan Todorov e François Hartog são muito interessantes e inspiradores.

Heródoto, considerado o pai da história, foi muitas vezes contestado pois algumas de suas afirmações foram desmentidas ou não comprovadas pelas escavações arqueológicas. Hartog, em seu livro O Espelho de Heródoto (1999), propõe a seguinte abordagem: em vez de invalidar o que Heródoto diz sobre o povo cita em suas Histórias, por terem sido desmentidas pela arqueologia, realizar um outro movimento, de buscar como Heródoto e os seus interlocutores, os gregos, representavam e compreendiam os outros, os não-gregos, e quais os significados dessa representação para os leitores. Nesse sentido, a "mentira" sobre os outros (o povo Cita) deixa de sê-lo e passa a ser um elemento constitutivo daquele discurso que remete o historiador para um imaginário sobre esse povo presente tanto no autor quanto nos seus interlocutores. 
Hartog propõe uma leitura, através da análise de elementos do próprio texto que leva o historiador, nesse caso, “...não 'para o lado' dos citas, mas 'para o lado’ dos gregos”. Através dessa leitura “... pode-se apreender quem são os citas de Heródoto, o que inclui também os citas do imaginário grego, uns remetendo aos outros reciprocamente ...” (HARTOG, 1999, p.52). Dentro do texto que fala sobre o outro chega-se, não ao outro de fato, mas ao outro do autor e também ao outro do destinatário, já que o “...destinatário está, com efeito, alojado no interior do próprio texto" (HARTOG, 1999, p.49).

No final das contas, encontramos o próprio autor e suas dimensões histórico-culturais. Analisando desta maneira um texto histórico, um documento, ou qualquer outro discurso, perde o sentido um mero julgamento de veracidade. O texto histórico e o documento ganham, assim, outro brilho: nem verdade, nem mentira, mas algo a ser analisado na sua própria complexidade.

Pensando nisso, proponho algumas considerações para um exercício de leitura do relato de Hans Staden e suas posteriores adaptações. Ao fazer esse exercício, passeamos por diversas temporalidades de eus e outros. Há um eu autor que descreve um outro desconhecido, pautado em outros conhecidos. Há eus muito distantes no tempo que utilizam esse relato desse outro, para falar de um outro ainda mais distante, chega-se por fim em eus e outros próximos, espectadores e autores que compartilham de um mesmo regime de historicidade.

\title{
RELATOS DE VIAGENS: falar do outro e descobrir o eu
}

\author{
-Resta uma cidade que você jamais menciona. \\ Marco Polo abaixou a cabeça. \\ -Veneza-disse o Khan. \\ Marco sorriu. \\ -E de que outra cidade imagina que eu estava falando? (CALVINO, 1990, p.82)
}

Esse diálogo, citado por Hartog (1999, p.268) quando analisa os relatos de viagens, levao à seguinte questão: “de que fala, no fim das contas, o viajante?". Ao falar sobre todas as outras cidades Marco Polo estava sempre falando da sua cidade, Veneza. Ou seja, ao falar do outro, falava de si, ao falar do diferente, falava do familiar. O viajante olha, e o que enxerga? Descobrir o que ele vê não é algo simples e direto, perceptível através da literalidade das palavras, pois o que o viajante descreve é uma interação entre um $e u$ em contato com aquele outro. Existe um $e u$ implícito na descrição do outro. Portanto, é preciso decifrar esse texto. 
Os índios, com a descoberta da América foram os outros dos europeus, e muitas foram as repercussões desse outro para o conhecimento que os europeus tinham de si. Ao descreverem, interpretarem, ou tentarem entender os índios, os europeus projetavam nessas figuras "estranhas" a sua própria concepção de mundo.

Os "descobrimentos" - o contato entre europeus e americanos, a descoberta do novo mundo e sua descrição - foram temas escolhidos por Tzvetan Todorov para abordar a questão do outro (TODOROV, 1996). E um ponto que o autor ressalta é como Colombo estava imbuído de idéias e ideais europeus, no seu contato com os índios, e como isso influenciou sua visão e sua descrição. Colombo olha para o outro, mas enxerga o que espera ver. Ou seja, ele não enxerga o outro, mas a expectativa que faz do outro: "Ele não se preocupa em entender melhor as palavras dos que se dirigem a ele, pois já sabe que encontrará ciclopes, homens com cauda e amazonas." (TODOROV, 1996, p.17). Quando vê algo acontecendo na sua frente, descreve-o como algo que já conhece: "A coisa acontece na sua frente, mas o que ele relata em seu diário é a explicação de Plínio, tirada de um livro..." (TODOROV, 1996, p.17)

Além de ver o outro com seus próprios olhos (como poderia ser diferente?), esses olhos que vê vem carregado de significações. Nesse eu que descreve um outro está presente muitos outros eus. Como escreveu Todorov, "pode-se descobrir os outros em si mesmo, e perceber que não se é uma substância homogênea, e radicalmente diferente de tudo o que não é si mesmo; eu é um outro. Mas cada um dos outros é um eu também, sujeito como eu." (TODOROV, 1996, p.3). Encontramos em nós mesmos a influência dos outros. Os nossos hábitos, os nossos pensamentos não estão isolados de uma cultura, de uma sociedade. Claro que isso não pode ser percebido de forma direta: um ser não é um reflexo da sociedade, mas ao mesmo tempo não é completamente individual, sem nenhuma ligação com os outros. Os outros também estão nesse $e u$.

\section{Duas viagens ao Brasil (Hans Staden, 1557)}

Hans Staden, um alemão da região de Hesse, publicou um relato sobre suas viagens à América durante os anos de 1547 e 1549. Apenas nos primeiros dez anos foi reeditado por mais de cinco vezes. Tornou-se um documento peculiar que atravessou o mar do tempo e permanece como leitura para os olhos contemporâneos. 
Apesar da sua narrativa trazer outros elementos que fazem parte da viagem, aqui vou descrever apenas alguns trechos nos quais o aventureiro entra em contato com uma tribo tupinambá, foco também dos filmes a serem analisados na sequência.

De acordo com o relato, Hans Staden fora capturado quando caminhava pela mata em busca de seu escravo que fora caçar. A partir daí, o autor passa a narrar o seu contato com os indígenas, tentando mostrar o quão bárbaros e ameaçadores estavam sendo com ele. Já nesse primeiro contato, Staden realiza uma espécie de milagre: os índios pedem que ele reze para que seu Deus fizesse desviar uma tempestade e isso ocorre. O autor vai mostrando como os índios eram bárbaros e ameaçadores e ao mesmo tempo, como aconteciam milagres que iam lhe poupando a vida.

Quando Staden chega à tribo, é rodeado por mulheres, o que caracterizaria o início do ritual antropofágico: "Algumas foram à minha frente, outras atrás, dansando (sic) e cantando uma canção que, segundo seu costume, entoavam aos prisioneiros que tencionavam devorar." [grifo meu] (STADEN, 1974, p.87). Neste trecho, é interessante destacar a frase "segundo seu costume", o que nos indica um conhecimento do aventureiro a respeito das práticas e costumes dos indígenas.

Staden continua a descrição, tentando mostrar os sofrimentos pelo qual passava:

Tiravam-me umas pelos braços, outras pelas cordas atadas ao pescoço, tão fortemente que eu quase não podia respirar. O que tinham em mente, quando assim me arrastavam, não sei. Pensei então nos sofrimentos do nosso salvador Jesus Cristo, como foi inocentemente torturado pelos vis judeus (...)consolei-me nêste pensamento e, mais resignado, tudo aceitei. (STADEN, 1974, p.89-90)

Para fazer compreender o que ele sentia e passava, associava seus sentimentos aos sofrimentos de Cristo, colocando-se numa posição de mártir e de alguém que tem certa intimidade com Deus.

Em um momento posterior, Staden descreve sua tentativa de convencer os índios de que não era português, mas não consegue. Um francês aparece na tribo e parece ser uma esperança para confirmar para os índios de que diz a verdade. Mas isso não acontece. E para piorar a sua situação, o francês afirma que Staden é português e que deve ser comido. Também é reconhecido por um outro índio como sendo amigo dos portugueses. A única maneira de mudar a idéia dos índios seria provar que não era português, mas tudo caminhava contra isso.

Numa noite, quando os chefes se reuniam ao luar, e discutiam sobre o destino de Staden, algo diferente aconteceu: “...estava triste, olhava a lua, e pensava comigo: 'Ó meu Senhor e meu 
Deus, tira-me dêste sofrimento para a bemaventurança'. Perguntaram-me então por que fitava sempre assim a lua, e respondi: 'Vejo nela que está zangada'." (STADEN, 1974, p. 102). Um diálogo é travado entre Staden e os indígenas e um deles pergunta com quem está zangada a lua e Staden responde: "Ela olha para a tua cabana". O índio fica furioso, mas no dia seguinte chega a notícia de que uma tribo de parentes dos tupinambás havia sido destruída. Partem para ajudar na reconstrução da aldeia e o ritual da morte de Staden também está sendo preparado. Ele fica ansioso, pois pode morrer a qualquer momento, basta que seu dono volte. Mas, os parentes de seu dono ficam doentes, e isso, segundo o relato, é interpretado pelos índios como sendo a ira do Deus de Staden. E o viajante confirma isso. E conclui: "que eu tenha desta sorte aludido à lua naquela noite, deve ter acontecido pela providência divina. Alegrei-me muito e pensei ainda: Hoje Deus está comigo!" (STADEN, 1974, p.107)

Tudo que é narrado passa a ter alguma relação com as ações de Staden e passa a ser interpretado como se ele tivesse algum poder divino. Um dia, estava lendo um livro em português, e conversou com um prisioneiro amigo dos portugueses, na noite seguinte houve uma tempestade e os índios achavam que eram por que Staden havia conversado com um amigo e tentava impedir que fosse devorado. Staden pediu que Deus o ajudasse e o dia seguinte amanheceu limpo.

Todos os elementos que são narrados têm um sentido e um objetivo. Ele descreve a noite do luar para mostrar a sua "sorte"; cita um menino que comia um pedaço de carne humana para em seguida mostrar que o infortúnio posterior se devia a isso, etc... Ou seja, ele não está querendo descrever e observar os índios, seus hábitos e costumes. O objetivo do seu relato era outro. E esse objetivo é apresentado no ínicio do texto.

O objetivo da própria escrita é um dado importante para compreender as escolhas narrativas e o rumo que a prosa toma. Hans Staden narra sua aventura pretensamente com o objetivo de mostrar como Deus havia sido generoso ao livrá-lo dos perigos encontrados.

Logo na dedicatória, o autor cita uma passagem do profeta David, com a qual se identifica:

Aqueles que singraram os mares, levando mercadoria aos grandes oceanos; aqueles que a obra do Senhor conheceram e, no mar, o seu poder testemunharam, quando falou e levantou uma tempestade, elevando-os aos céus nas vagas e descendo-os aos abismos, de almas angustiadas, e esmorecidos, cambaleantes, incertos como ébrios, desesperançados de qualquer alento; aqueles que clamaram de sua miséria ao Senhor e êle os tirou de sua angústia, acalmando o furacão, e fazendo espraiar-se as ondas suavemente, e voltar-lhes a alegria porque as ondas assim se acalmaram, trazendo-os à 
terra procurada devem agradecer ao Senhor pela bondade e poder com que agraciou aos seus filhos, e louva-lo com os seus irmãos e exalta-lo com os seus patriarcas. (STADEN, 1974, p.25)

Staden se identifica com a profecia de David, e acredita que fora salvo pela "Vontade Divina" ao passar pelos infortúnios, como podemos perceber na passagem seguinte: "Agradeço, pois, ao Creador (...) pela grande graça e misericórdia que (...) me foram concedidas maravilhosa e inesperadamente, quando eu, no Brasil, caí em poder dos selvagens, os tupinambás, ficando nove mêses seu prisioneiro, e tendo escapado a muitos outros infortúnios." (STADEN, 1974, p.25-26) Pelo trecho, percebemos que o autor se descreve como sendo um recebedor de graças divinas "maravilhosas e inesperadas". Ele se descreve como um personagem privilegiado, agraciado por Deus, cujo objetivo narrativo é comprovar essa idéia: “...peço ao leitor queira considerar o que escrevo. Dou-me a este trabalho, não pelo prazer de escrever alguma coisa nova, mas exclusivamente para trazer à luz os benefícios que Deus me prestou!" (STADEN, 1974, p.121)

Em outro trecho, o objetivo é novamente reiterado:

De certo tinha eu também muito mais para escrever, se para tanto me esforçasse, mas o meu intuito não era êsse. Expús, aqui e alí, suficientemente, o pensamento que me levou a escrever êste livrinho, a saber, como todos nós devemos a Deus louvor e gratidão, por ter-nos protegido desde o nascimento, desde a primeira hora, até as presentes, em nossa vida. (STADEN, 1974, p.196)

Esse é um elemento que vai permear toda sua narrativa. Ao escrever sua história, depois de ocorrida a aventura, busca justificar tudo o que ocorreu pela Vontade Divina. E, a partir daí, atribui esse significado aos acontecimentos. Essa insistência em reafirmar o objetivo da escrita pode ter outros significados que mereceriam uma análise mais profunda, que não cabe nos limites deste texto e deste autor.

A necessidade de Staden mostrar que, quando solicitado, Deus o ajudou pode ter relação com o fato de o narrador ser protestante, já que, para essa religião, o fiel consegue entrar em contato direto com Deus sem intermediários. Sendo assim, o texto poderia ser interpretado como uma obra de divulgação religiosa, ainda mais no contexto de disputas entre católicos e protestantes em que vivia a Europa no século XVI.

A religiosidade é o tom predominante assumido pelo texto. Staden escreve para um público que compreende essa linguagem, e aceita que Deus o ajudou. Segundo Fleischamann (1991) a necessidade de afirmar insistentemente a veracidade do relato é um indício da tendência 
do público a não acreditar nesse tipo de narrativa. No entanto, essa incredulidade não estaria relacionada a uma falta de religiosidade. O século XVI é um século de crenças, de religiosidade, de brigas religiosas.

Portugueses, Espanhóis, Italianos, Franceses: todos, durante anos, durante decênios, se orgulham de que melhor do que correr o mundo como mercadores, é navegar, combater, desbravar todos os riscos antes do mais, para alargar os limites da cristandade...São homens de ação, mais do que críticos. São ...obsidiados completamente por um grande sonho de unificação do mundo cristão, de incorporação, à cristandade renovada, de povos até então estranhos e hostis ao cristianismo. (FEBVRE, s/d, p.502)

A miséria, a busca de riquezas talvez também fossem motivos que movessem os homens em seus intentos, mas a justificativa religiosa não pode ser ignorada.

A memória que os viajantes sugerem em seus relatos é medieval (adjetivo): impregnada de religiosidade, destaca-se em suas manifestações o amor-temor a Deus e ao Diabo; (...)Se a incredulidade, como demonstrou Lucien Fèbvre, era impossível no século XVI (quando foi ou será?), não é novidade alguma demonstrar isso novamente, relacionando expressões tiradas desses relatos apenas para provar o que já está provado. (MICELI, 1998, p.33)

Nesse sentido, podemos supor que o público leitor de Staden era um público que acreditava e talvez até valorizasse uma narrativa de vanglória ao poder do seu Deus. Em alguns momentos, Staden apresenta a sua situação de forma bastante desfavorável, o que gera o efeito posterior de que a ajuda divina foi ainda maior. Chega numa situação que parece sem saída, mas consegue escapar pela "força divina".

Como não poderia ser diferente, Hans Staden, como um viajante e narrador, assumia posturas semelhantes às descritas por Todorov no que diz respeito aos viajantes do Novo Mundo: ao narrar sobre seu contato com os indígenas já tinham uma idéia pré-concebida e narrava a partir de referênciais já conhecidos.

Isso é particularmente aplicável no tratamento do tema do canibalismo, aventura central do livro. Alguns autores questionam a maneira como foram lidas as idéias de canibalismo presentes nos relatos de viajantes quinhentistas (FLEISCHAMANN, 1991). Esses autores levantam uma problemática semelhante a encontrada na descrição de Heródoto do povo Cita:

[...] tanto o 'lugar do crime' como a realidade dos fatos canibalísticos desapareceram para sempre. O que nos resta são textos, que não são aptos para uma investigação do tipo positivista. Estes textos não documentam apenas a 'realidade', eles tem funções sociais, tradições e legitimações próprias. (FLEISCHAMANN, 1991, p. 128)

Como querer saber sobre esse outro indígena, e supostamente canibal, a partir de um relato escrito por europeu, cujo objetivo e público leitor está focado em outros europeus do 
século XVI? Staden não fala dos índios "reais", ele fala de um imaginário criado em torno do Novo Mundo.

O canibalismo no Brasil é mencionado pela primeira vez por Américo Vespúcio, cujas cartas eram de uma leitura bastante freqüente na Europa: “... constituiu-se através delas, uma imagem do Brasil como "terra dos canibais"..." (FLEISCHAMANN, 1991, p.131). Ou seja, criou-se um imaginário em torno dessas figuras "que comem gente".

Escrever sobre o canibalismo era também uma forma de agradar ao público, no caso de Hans Staden e Jean de Lery:

O tema canibalismo, na sua tradição já estabelecida, correspondia ao gosto de leitores amantes de história curiosas e de aventuras, cuja autenticidade não os preocupava. Correspondia também aos interesses dos colonos e à razão estatal, à busca de argumentos a favor da escravidão dos índios e aos interesses da igreja que buscava razões para sua missão civilizatória. (FLEISCHAMANN, 1991, 139)

Segundo esses autores, o fato de os viajantes descreverem o ritual de antropofagia de forma tão detalhada e semelhante, leva a crer que se basearam numa narrativa anterior. $\mathrm{Na}$ descrição de Staden, por exemplo, num determinado momento, quando ele é capturado pelos índios e achava que seria comido, sua postura foi de procurar “... em torno pelo ibira-pema, a maça com que executam os prisioneiros" (STADEN, 1974, p.90). Ou seja, ele já sabia anteriormente o que iria encontrar e já procurava por ela. É uma narrativa pautada em pressupostos que condicionam o olhar.

Assim, como poderíamos compreender os índios nessa narrativa? Que índios são esses descritos? Não podemos considerar que essa seja uma "verdade" sobre os índios, e que tudo que aparece ali é baseado num olhar neutro do viajante. Ele pode até descrever o que viu, mas o que vê ganha sentido a partir do que ele já conhece sobre o assunto: “...se você não pode dizer senão o que viu, não pode ver senão o que é dito...” (HARTOG, 1999, p.261)

Dentro dessa perspectiva, quem é esse $e u$ (Staden) que fala sobre um outro? Assim como em Heródoto cujo outro sobre o qual fala o autor, não é o outro real, mas, o outro que está no imaginário tanto do autor, quanto dos seus interlocutores. Assim, os índios descritos por Staden e tudo que vivenciou na tribo nos remete muito mais a um imaginário europeu sobre como deveriam ser os "selvagens" índios do que aos índios em si. Isso não significa "invalidar" o relato como "inverídico", mas compreender sobre quem e sobre o que ele fala. 


\section{DUAS VIAGENS RELIDAS: transcriações cinematográficas}

Muitos e muitos anos depois da publicação de Duas viagens ao Brasil, a aventura de Hans Staden ganha visibilidade cinematográfica. O relato foi usado como documento para duas produções cinematográficas que tematizaram o encontro do branco europeu com a vida indígena no Brasil do século XVI.

Os dois filmes, Hans Staden (Luiz Alberto Pereira, 1999) e Como era gostoso o meu francês (Nelson Pereira dos Santos, 1971) usaram a narrativa de Staden para construir a sua própria narrativa. Da mesma maneira que o relato do viajante, os filmes são construídos com um propósito, um objetivo e ao falar do outro falam muito mais de si mesmos. Tentarei mostrar como os dois filmes têm leituras distintas de uma mesma obra de base e revelam concepções distintas sobre o passado tematizado no cinema.

Enquanto um busca a neutralidade, o outro, pelo contrário, assume claramente um ponto de vista. Enquanto um se apresenta como uma narrativa que fala do passado, o outro usa o passado para falar do presente. O objetivo de Luiz Alberto Pereira é "mostrar o Brasil do século XVI", enquanto o de Nelson Pereira é falar do seu tempo presente. São dois olhares e dois objetivos diferentes.

Ao utilizar um texto como base para uma obra cinematográfica, ou fazer qualquer outro tipo de adaptação, é importante uma boa leitura da obra de base em toda complexidade e não apenas na sua literalidade. Ou seja, fazer uma leitura "histórica" desse texto tentando perceber como e com quais objetivos construiu-se a narrativa, com que elementos está dialogando e principalmente qual o seu público alvo. Não basta considerar que o texto é uma janela para a realidade, como vimos anterioremente.

Os dois filmes têm leituras distintas da mesma obra e também objetivos distintos. Há também diferenças na concepção de história. O diretor de Hans Staden declara que “... minha idéia foi transpor para a tela algo nunca feito antes, mostrando como era de fato o Brasil do século 16" (PEREIRA, 2000, p.11).

Esse objetivo, o de mostrar o Brasil "como era no século XVI", vai direcionar a leitura da obra de base e levá-lo à utilização do relato do viajante de maneira literal. A narrativa do filme Hans Staden é construída seguindo-se a mesma seqüência do relato do viajante. E como parece 
não ter havido uma leitura crítica desse relato, uma contextualização e uma compreensão daquela obra, o filme adquire um aspecto meramente descritivo e parece não querer dizer nada.

As ações de Staden, que têm funções específicas no relato escrito, perdem seus significados e parecem não adquirir um novo significado no filme de Luiz Pereira. Enquanto na narrativa de Staden todos os elementos caminham no mesmo sentido, de forma a comprovar a sua tese, como vimos anteriormente, o filme parece solto. Ele utiliza de maneira literal o texto de Staden e parece acreditar com isso que está sendo imparcial e "verdadeiro".

Ingenuidade. Não é possível ser neutro. E um filme não pode mostrar "como era de fato o Brasil do século XVI" só porque se baseia em um relato de um viajante que "esteve" no local e “descreveu" aquelas pessoas. Entre falar sobre o outro (Staden) para chegar no outro (índio) há um processo complexo de alteridades e identidades.

Ao contrário, o filme de Nelson Pereira tem significados e objetivos, não pretende ser neutro. Sua narrativa não é uma transposição de fatos, mas a construção de idéias através de vários elementos históricos.

Por exemplo, se tomarmos a representação do ritual antropofágico/canibalístico em cada um dos filmes ele ganha um significado. Em Como era gostoso o meu francês, o ritual antropofágico (e não canibalístico) é um elemento central da narrativa, a começar pelo próprio título do filme. E esse ritual aparece como uma metáfora (e uma referência cultural simbólica) e uma alusão aos seus significados políticos posteriores, principalmente porque o personagem do estrangeiro, um francês, é de fato comido no final do filme. Essa escolha tem um significado importante, como analisa Ismail Xavier: "A incursão bem-humorada pelo Brasil do século XVI se desdobra em profecia sinistra, pois o rito antropofágico que deglute o francês se acompanha da sua advertência vingativa: seu povo virá em número cada vez maior para 'acabar com os índios'" (XAVIER, 1998, p.166-167).

Em Hans Staden esse ritual, assim como a maioria dos elementos do filme, aparece estritamente atrelado à descrição de Staden, sem outros significados, sem tomada de posição. Essa postura de busca de "neutralidade" nos remete a uma situação histórica na qual o filme foi produzido.

Lucia Nagib levanta um aspecto importante das produções cinematográficas da década de 1990, principalmente, que é a adoção de um comportamento acrítico por parte dos filmes. Uma 
das grandes diferenças entre Hans Staden e Como era gostoso meu francês está ligada a esse aspecto, já que um quer ser neutro e o outro escancara o ponto de vista.

Em todos esses filmes novos, a aspiração do futuro (a esperança revolucionária) dá lugar a uma pesquisa arqueológica (o mito da origem), que procura desencavar fatos históricos a fim de reconstruir a imagem de um personagem individual ligada a uma paisagem e a uma cultura, para só então quem sabe - num segundo momento - pensarse em propostas de transformação. (NAGIB, 2000, p.125)

Essa vontade de ser "neutro" dos filmes está muito ligada ao momento histórico descrito pela autora. Num artigo publicado pelo Jornal Folha de São Paulo, essa idéia aparece de maneira mais clara no que se refere ao filme Hans Staden:

'Hans Staden" limita-se ao relato factual. Em nenhum momento percebemos as "intenções" do diretor. O crítico de cinema fica atônito diante de obra tão dura, tão objetiva, tão parca em significados e intenções de autor. (...). Narra um episódio, simplesmente. O episódio está tão distante das habituais 'interpretações do Brasil', furta-se (...) à miragem do 'significado'. (...) Diz apenas: 'Foi desse jeito". Seu objetivismo conduz à falta de empatia. O filme é interessante, mas não emociona. Recusa-se a todo raciocínio fácil em torno da questão 'o que é o Brasil'. Talvez isso seja um sinal de maturidade. Estamos tão entupidos, neste ano 2000, de interpretações, de visões retrospectivas, de culpabilizações históricas, de raciocínios a respeito do Brasil, que é sinal positivo dessa overdose a existência de um filme neutro, distante, frio, como 'Hans Staden'. Libera-nos de nosso passado. (COELHO, 2000, s/p)

Esse artigo exalta a neutralidade como qualidade em função de uma suposta saturação de interpretações. Ou seja, o passado não é visto como "origem" de algum problema atual, ou as "causas" dos desdobramentos futuros da nação, algo que aparece no filme de Nelson Pereira. O filme é elogiado por esse autor exatamente porque o passado representado é livre de interpretações.

Mas isso não significa que o filme consiga ser "neutro". A neutralidade também produz discursos e reproduz discursos, como nos alerta Morettin, no caso desse filme:

Certo é que "mostrar" o século XVI a partir do ponto de vista de um europeu imbuído dos preceitos civilizatórios significaria assumir um tipo de discurso sobre o outro que não se coaduma mais com as reflexões acerca do que representou a presença do elemento branco neste território no decorrer do período colonial. (MORETTIN, 2000)

Essa suposta neutralidade nos remete a um tipo de pensamento sobre o passado bastante criticado, por exemplo, por Roland Barthes (1988), que, ao analisar os elementos lingüísticos do texto histórico positivista, observa como a forma de organização do enunciado pode levar a uma idéia de objetividade, fazendo com que desapareça aquele que enuncia, o que faz com que "a história [pareça] se contar sozinha". Nesse filme há uma ausência do sujeito do discurso numa postura supostamente "neutra" da narrativa: ninguém assume a autoria do relato. 
Postura presente em alguns filmes históricos que transparece, por exemplo, em cenários, figurinos e personagens. O cenário deve ser feito de forma a reconstituir o ambiente em que 'realmente' se passou a cena representada. As falas dos personagens devem estar de acordo com a época, e os figurinos devem combinar com os personagens. Tudo isso baseado numa boa 'pesquisa histórica', que dá um tom de "cientificidade" e, assim, maior credibilidade ao filme. Ela "possibilita a reconstituição (palavra por demais usado no vocabulário crítico) e esta, se for 'autêntica', nos transmite a impressão de naturalismo." (BERNARDET, 1982, p.64)

Esse tipo de postura aparece na fala do diretor de Hans Staden, para quem o realismo do filme é a sua

[...] grande virtude.(...). Meus índios estão nus como os daquela época. Não usam as sunguinhas de penas que os da Globo vestem. As cores das penas que os índios utilizavam foram mantidas. Até as chuvas foram verdadeiras, lá em Ubatuba. Nada de filme tropicalista, coloridão. Contratamos também um professor que até gramática tupi ensinou para os meus atores, e eles conseguiram me contar piadas em tupi. (PEREIRA, 2000, p.11)

José Geraldo Couto, numa passagem que gosto muito, ao criticar esse tipo de postura no filme A Guerra de Canudos, coloca uma questão importante: “...talvez esse mimetismo exterior, de superfície, não seja a melhor maneira de o cinema tentar se aproximar de uma realidade ou ao menos da "sua verdade"” (COUTO, 1997). Será que a melhor maneira de um filme, que aborda uma temática do passado, construir sua "verdade" seria se apegar a aspectos factuais e materialmente "fidedignos" na construção de um passado pautados em documentos e relatos que são, em si mesmos, cheios de complexidades como é o caso do relato de Hans Staden?

E voltamos à questão da leitura. Ao buscar simplesmente a "verdade" da obra de base, seja ela ficcional ou historiográfica, sem se compreender que aquele é um discurso, e que o próprio filme é um discurso e que não é possível ser neutro, cria-se uma obra cinematográfica pobre que exalta a "fidelidade" em detrimento do cinema.

Uma postura muito diferente adota o diretor Nelson Pereira: "Como era gostoso... é uma invenção minha, evidentemente baseada em todos os cronistas da época: Hans Staden, Jean de Lery, os jesuítas, mas basicamente é a aventura de Hans Staden. Aquele filme é uma parábola sobre a ditadura..." (SANTOS, 1998, p.16) A sua relação com o passado é outra, não uma aceitação sem crítica, mas um olhar desconfiado, que questiona as narrativas sobre o passado para construir a sua própria. Segundo Ismail Xavier, o filme de Santos incorpora a tradição das 
descrições "...para deslocar perspectivas, desconfiar de versões oficiais, aludir à violência recalcada por discursos civilizatórios." (XAVIER, 1998, p.166-167)

Os dois filmes têm a mesma temática, mas abordadas de maneiras completamente diferentes, o que nos revela posturas diferentes em relação à própria história e a representação do passado pelo cinema.

O filme de Nelson Pereira nos fala sobre o cinema da década de 1970 e sobre uma determinada postura frente à cena política da época e vem imbuído de idéias e propostas de transformação. Sua postura contrária ao regime estabelecido e suas propostas de mudança a partir dos "vencidos" levam-no a olhar para história como aquela escrita pelos "vencedores", sendo assim, algo a ser contestada. A história assume claramente uma relação direta com as lutas do presente.

Em Hans Staden, como vimos, a busca de neutralidade é quase "sintoma" de uma geração saturada de "significados" que parece precisar "exorcizar" o legado deixado pelas gerações anteriores.

Falar sobre o passado é também falar sobre o outro, e falar do passado (outro) é também falar de si mesmo. Em Como era gostoso meu francês o eu do autor está presente e identifica o próprio tempo, enquanto o eu do autor de Hans Staden parece querer se esconder numa suposta neutralidade de um olhar para o passado. No entanto, o eu que se anuncia ou o $e u$ que se esconde gritam sobre si mesmos e demonstram visões sobre a sociedade do presente na qual os produtores dos discursos estão inseridos. 


\section{Referências}

BARTHES, Roland. Da história ao real in: O Rumor da língua. trad: Mário Laranjeira. São Paulo: Brasiliense, 1988

BERNARDET, Jean Claude. Qual é a história? In: Piranha no mar de rosas. São Paulo: Nobel, 1982

CALVINO, Ítalo. As cidades invisíveis. Trad: Diogo Mainardi. São Paulo: Companhia das Letras, 1990

COELHO, Marcelo. Neutralidade é qualidade em Hans Staden In: Folha de São Paulo, Ilustrada, edição eletrônica, 29/03/2000

COUTO, José Geraldo. 'Canudos’ é submisso à realidade do massacre. Ilustrada, Folha de São Paulo, 3/10/97

FEVBRE, Lucien. O Problema da Descrença no Século XVI: A Religião de Rabelais. Lisboa: Editorial Início, s.d ${ }^{1}$

FLEISCHMANN, Ulrich; ASSUNÇÃO, Matthias Rohrig; ZIEBELL-WENDT, Zinka. "Os Tupinambá: Realidade e Ficção nos Relatos Quinhentistas" Revista Brasileira de História São Paulo: ANPUH/Marco Zero, vol.11, n ${ }^{\circ} .21$ - setembro 90/fevereiro 91 - pp.125-145

HARTOG, François. O Espelho de Heródoto: ensaio sobre a representação do outro. Trad: Jacyntho Lins Brandão. Belo Horizonte: Ed. UFMG, 1999

MICELI, Paulo. O Ponto onde estamos: viagens e Viajantes na História da Expansão e da Conquista (Portugal, séculos XV e XVI). 3ª . Edição. Campinas, SP: Editora da UNICAMP, 1998

MORETIN, Eduardo V. "Hans Staden: o indivíduo e a História". In: Sinopse Revista de Cinema, n 5 - São Paulo: CINUSP, junho/2000

NAGIB, Lúcia. "O novo cinema sob o espectro do Cinema Novo" in: Estudos de cinema Socine II e III - São Paulo: AnnaBlume, 2000

PEREIRA, Luiz Alberto, entrevista concedida a Paulo Santos Lima "Hans Staden mostra os dentes no cinema" - Folha de São Paulo, Ilustrada p.5-11 - edição eletrônica - 17/03/2000

SANTOS, Nelson Pereira. Campo e contracampo - A tela caleidoscópica de Nelson Pereira dos Santos - Entrevista concedida à Revista Sexta Feira, n ${ }^{\circ} .3$ - fronteiras, São Paulo: Pletora Editora, outubro 1998 
STADEN, Hans. Duas Viagens ao Brasil. Trad: Guiomar de Carvalho Franco/ transcrito em alemão moderno por Carlos Fouquet. Belo Horizonte: Ed. Itatiaia; São Paulo: Ed. Da Universidade de São Paulo, 1974

TODOROV, Tzvetan. A conquista da América: a questão do outro. Trad: Beatriz Perrone Moisés. São Paulo: Martins Fontes, 1996

XAVIER, Ismail. Eldorado como inferno - Cinema Novo, Pós-Cinema Novo e as apropriações do imaginário do Descobrimento. Revista Sexta Feira, n ${ }^{\circ} .3$ - fronteiras, São Paulo: Pletora Editora, outubro 1998 